\title{
THE AED tRAINER BOX: MAKING AED tRAINING EASIER FOR the COMMUNITU
}

CLINT JEAN LOUIS FERNANDEZ, DIEGO REYERO DIEZ, CARLOS BEAUMONT CAMINOS, JAVIER FERNANDEZ EITO, LLUNA MARTINEZ, NIKOLE VELILLA MENDOZA NAVARRA HEALTH SERVICES; EL ABC QUE SALVA VIDAS, Navarra, Spain

\section{INTRODUCTION:}

Spread BLS-AED skills far and wide in the community

AEDs are increasingly made available around the community as one of the key components of the Chain of Survival. BLS-AED training is fundamental to increase bystander CPR rates and improve survival. Good quality and realistic AED trainers are still expensive and access restricted to health care professionals and first responders.

\section{OB JECTIVES:}

Anyone using an AED can restart a heart

To develop a simple, attractive, and reasonably priced AED simulator which can be extensively employed to spread knowledge of BLS and AED use.

\section{MATERIALS AND METHODS:}

Design thinking tools were employed to study training needs of the users in school settings.

A single product consisting of an app and a carton box is developed to simulate the AED. The initial focus group for users is the secondary school community involving teachers and students who already receive $B L S$ training

\section{RESULTS:}

Teacher feed back was crucial to box design and app specifications

A combined app and several box prototypes to hold a phone/tablet are developed with potential user feedback.

The single app has two options: instructor use or student use.

Teachers are able to program case scenarios

based on learning goals and evaluate

groups/individuals as they apply BLS and use the AED simulator (Checklists).

These evaluations can be sent to the students and stored for future reference and comparison.

Student use converts a phones display into an

AED.

The app is applicable on smart phones, tablets and also web based to facilitate teacher access.

\section{CONCLUSIONS:}

A reasonably priced quality $B L S$ AED trainer may soon be available for all.

The AED trainer box is a potential tool to spread the knowledge of BLS-AED and for regular training in the community. It can be used by other first responders (police, life guards, firemen) health care professionals,students and citizens in general for teaching and training purposes.

\section{MAKE + LEARN + TEACH + TRAIN + SPREAD}
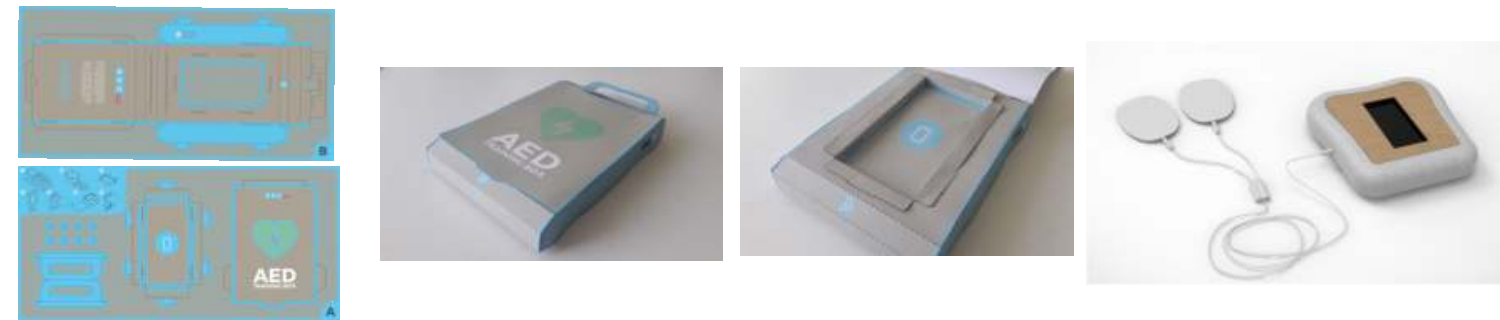
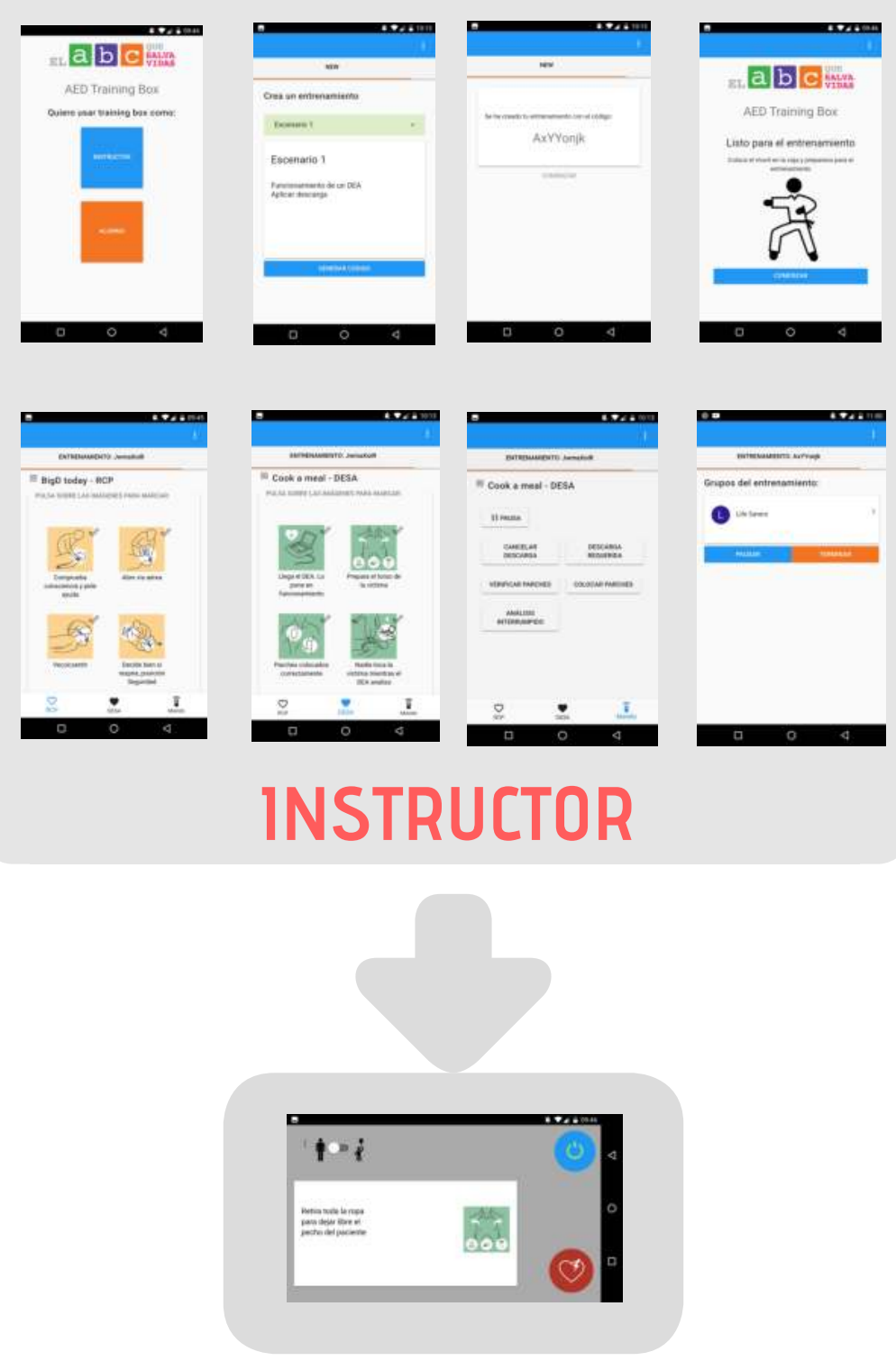

STUDENT 